\title{
PERAN MEDIATOR KEPUASAN UNTUK MENGALOBORASI KUALITAS PELAYANAN, CITRA DAN PENANGANAN KOMPLAIN TERHADA LOYALITAS (STUDI PASIEN BPJS DI RUMAH SAKIT ISLAM AMAL SEHAT SRAGEN)
}

\author{
THE ROLE OF THE MEDIATOR OF SATISFACTION TO \\ COLLABORATE THE QUALITY OF SERVICE, IMAGE AND \\ COMPLAIN HANDLING ON LOYALTY (STUDY OF BPJS \\ PATIENTS OF AMAL SEHAT ISLAMIC HOSPITAL OF SRAGEN)
}

\author{
ARIS TRI HARYANTO \\ SEPTIANA NOVITA DEWI \\ Sekolah Tinggi Ilmu Ekonomi AUB Surakarta \\ Email: Arisharyanto26@yahoo.co.id
}

\begin{abstract}
ABSTRAK
Penelitian Rumah sakit sebagai institusi pelayanan kesehatan sekaligus sebagai entitas yang memiliki tanggung jawab kepada shareholder dan stakeholder harus jeli dalam melihat perubahan-perubahan yang dikarenakan kemajuan teknologi, pengaruh globalisasi, tingkat persaingan yang semakin tinggi dan perilaku pasien BPJS yang semakin kritis dalam memilih pelayanan kesehatan. Tujuan penelitian ini adalah melihat peran peran mediator kepuasan untuk mengaloborasi kualitas pelayanan, citra dan penanganan komplain terhada loyalitas pasien BPJS di Rumah Sakit Islam Amal Sehat Sragen.teknik analisis yang digunakan adalah analisis jalur dengan jumlah sampel sebesar 80 pasien. Hasil penelitian ini menunjukkan Kualitas pelayanan berpengaruh positif dan signifikan terhadap Kepuasan Pasien BPJS. Citra berpengaruh positif dan signifikan terhadap Kepuasan pasien BPJS. Penangganan Komplain berpengaruh positif dan tidak signifikan terhadap Kepuasan Pasien BPJS. Kualitas Pelayanan, Citra rumah sakit berpengaruh positif dan signifikan terhadap Loyalitas Pasien BPJS. Kepuasan pasien BPJS dan penanggan komplain berpengaruh positif dan tidak signifikan terhadap Loyalitas Pasien BPJS. Hasil analisis jalur menunjukkan bahwa pengaruh langsung kualitas pelayanan terhadap loyalitas pasien BPJS dan Citra terhadap loyalitas pasien BPJS lebih efektif dibandingkan pengaruh tidak langsung, sehingga untuk meningkatkan loyalitas pasien BPJS lebih efektif melalui jalur langsung.
\end{abstract}

Kata Kunci: Kualitas Pelayanan, Citra, Penanganan Komplain, Kepuasan, Loyalitas.

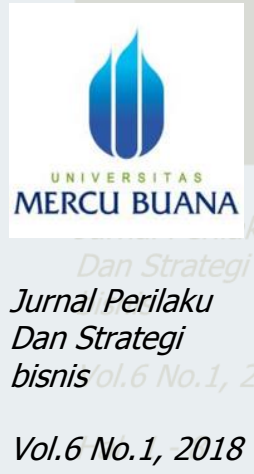

Hal. 1 - 8

\begin{abstract}
Hospital research as a health service institution as well as an entity that has responsibilities to shareholders and stakeholders should be keen in seeing the changes due to technological advances, the influence of globalization, the increasing level of competition and the behavior of BPJS patients who are increasingly critical in choosing health services. The purpose of this study is to see the role of mediator satisfaction to analyze the quality of service, image and
\end{abstract}


handling complaint to the loyalty of BPJS patients in Amal Sehat Islamic Hospital of Sragen. The analytical technique used was path analysis with total sample of 80 patients. The results of this study indicate that service quality has a positive and significant effect to BPJS Patient's satisfaction. The image has a positive and significant effect on BPJS patient's satisfaction. Complaint handling has positive and insignificant effect on BPJS patient's satisfaction. Quality of service, image of the hospital have a positive and significant impact on the loyalty of BPJS patients. BPJS patients' satisfaction and complaint handling have positive and insignificant effect on the loyalty of BPJS patients. The result of path analysis shows that the direct influence of service quality on BPJS patient loyalty and image to BPJS patient loyalty are more effective than indirect influence. Therefore, to increase the loyalty of BPJS patient is more effective through direct line.

Keywords: Service Quality, Image, Complaint Handling, Satisfaction, Loyalty.

\section{PENDAHULUAN}

Perkembangan kesehatan Kabupaten Sragen sebagai salah satu bagian upaya pembangunan kesehatan nasional diarahkan untuk mencapai kesadaran, kemauan dan kemampuan untuk hidup sehat bagi setiap penduduk agar dapat mewujudkan derajat kesehatan yang optimal, upaya kesehatan yang semula dititik beratkan pada upaya penyembuhan penderita secara berangsur-angsur telah berkembang kearah upaya kesehatan promotif dan preventif (Profil Kesehatan Kabupaten Sragen Tahun 2013). Keberhasilan seorang manajer sebuah rumah sakit tidak hanya diukur dari kemampuannya untuk mendapatkan laba yang tinggi atau kemampuannya untuk menghemat biaya seminimal mungkin. Untuk mengukur kinerja didalam rumah sakit diperlukan sistem pengukuran kinerja yang tidak hanya mengukur aspek keuangan saja tetapi juga mempertimbangkan aspek non keuangan seperti kepuasan costumer, kualitas produk atau jasa, loyalitas karyawan dan sebagainya, sehingga pihak manajemen perusahaan dapat mengambil keputusan yang tepat untuk kepentingan hidup perusahaan dalam jangka panjang.

Dalam mewujudkan cita-cita dibidang kesehatan Kabupaten Sragen telah meletakkan visi pembangunan kesehatan di Kabupaten Sragen. Makna dari Visi tersebut mengandung harapan terhadap masyarakat Kabupaten Sragen pada tahun 2013 hidup dalam lingkungan dan dengan perilaku hidup sehat, memiliki kemampuan untuk menjangkau pelayanan kesehatan yang bermutu secara adil dan merata, serta memiliki derajat kesehatan yang setinggi-tingginya yang sejajar dengan kawasan maju di daerah lain.

RSUI Amal Sehat Sragen merupakan rumah sakit negeri yang berlokasi di Kabupaten Sragen, Jawa tengah. RSUI Amal Sehat Sragen menjadi rumah sakit pilihan dan telah memiliki pasien BPJS dari berbagai daerah di sekitar Kabupaten Sragen seperti Kabupaten Ngawi Jawa Timur, Grobogan, Karanganyar dan masyarakat Sragen sendiri. Pada umumnya RSUI Amal Sehat Sragen selain memberikan pelayanan pasien BPJS secara individu juga melayani pasien BPJS karyawan perusahaan dank lien perusahaan asuransi. Guna memenuhi kebutuhan dan harapan pasien BPJS RSUI Amal Sehat Sragen terus mengembangkan Pusat Layanan Unggulan atau center of Excellent dan Diagnostic Center yang lengkap dengan peralatan kedokteran terkini guna mendukung diagnosa secara akurat.

Dengan demikian rumah sakit dituntut untuk selalu menjaga kepercayaan masyarakat dengan meningkatkan kualitas pelayanan yang ada. Rumah sakit perlu secara cermat menentukan kebutuhan pasien BPJS sebagai upaya untuk memenuhi keinginan dan meningkatkan kepuasan pelayanan yang diberikan. Memberikan pelayanan dengan kualitas terbaik, bukanlah sesuatu yang mudah bagi pengelola rumah sakit karena pelayanan yang diberikan oleh rumah sakit menyangkut kualitas hidup para pasien BPJSnya sehingga bila 
terjadi kesalahan dalam tindakan medis dapat berdampak buruk bagi pasien BPJS. Dampak tersebut dapat berupa sakit pasien BPJS bertambah parah, kecacatan bahkan kematian. Rumah sakit sebagai bagian dari sistem kesehatan nasional dituntut untuk meningkatkan kualitas penyediaan fasilitas, pelayanan dan kemandirian. Untuk itu rumah sakit merupakan salah satu pelaku pelayanan kesehatan yang kompetitif harus dikelola oleh pelaku yang mempunyai jiwa wirausaha yang mampu menciptakan efisiensi, keunggulan dalam kualitas pelayanan, keunggulan dalam inovasi serta unggul dalam merespon kebutuhan pasien BPJS. Visi RSUI Amal Sehat Sragen adalah menjadi pilihan utama masyarakat dan rujukan dalam pelayanan kesehatan. Sedangkan misi RSUI Amal Sehat Sragen adalah menyelenggarakan pelayanan prima dengan mengutamakan kepuasan pelanggan, menerapkan pelayanan kesehatan sesuai dengan perkembangan ilmu pengetahuan dan tekhnologi serta didukung oleh sumber daya manusia yang professional berperan serta dalam mensejahterakan masyarakat melalui pelayanan kesehatan menjalin kemitraan dengan seluruh pihak terkait. Sehingga untuk dapat mencapai visi dan misi RSUI Amal Sehat Sragen perlu meningkatkan kualitas pelayanan dan penanganan komplain tujuannya adalah loyalitas pasien BPJS. Atas dasar uraian di atas, berdasarkan fenomena dan kajian teori yang dinyatakan oleh para ahli berhubungan dengan pentingya loyalitas pasien BPJS, maka dalam penelitian ini akan dikaji lebih mendalam berkaitan dengan loyalitas pasien BPJS RSUI Amal Sehat Sragen.

Kepuasan pasien BPJS menempati posisi penting dalam praktek di dunia bisnis, karena manfaat yang dapat ditimbulkannya bagi rumah sakit. Pertama, banyak peneliti setuju bahwa pasien BPJS yang terpuaskan cenderung akan menjadi loyal. Kepuasan pasien BPJS didefinisikan sebagai evaluasi pasca pembelian pasien BPJS suatu pelayanan atau jasa. Setelah melakukan pembelian barang dapat dilihat apakah pasien BPJS tersebut mengalami kekecewaan dalam menggunakan jasa atau pasien BPJS tersebut memperoleh atau merasa puas dengan pelayanan tersebut. Pasien BPJS yang merasa puas akan tetap memakai pelayanan atau jasa tersebut, tetapi pasien BPJS yang merasa kecewa akan meninggalkan pelayanan atau jasa tersebut dan akan ganti dengan pelayanan atau jasa lainnya. (Zeithaml, 2008)

Hasil penelitian yang relevan dilakukan oleh Endriyastono (2014), Suparno (2014), Henri (2005), Karsono (2005), Palilati (2007), Wenny dan Halim (2008), Semuel dan Wijaya (2009), Jan (2006), Eva Monica (2014) menunjukkan bahwa kepuasan berpengaruh signifikan terhadap loyalitas. Hasil penelitian yang relevan dilakukan oleh Kristian Suhartadi (2014) bahwa kepuasan berpengaruh tidak signifikan terhadap loyalitas. Kesenjangan antara teori hubungan antara kepuasan dengan loyalitas dengan temuan hasil penelitian (teori gap) dan kesenjangan antara temuan hasil penelitian (riset gap) telah menimbulkan rasa ingin tahu untuk mengkaji lebih mendalam hubungan ke dua variabel yaitu pengaruh antara kepuasan terhadap loyalitas pasien BPJS merupakan arah pengaruh yang dikaji dalam penelitian ini.

Kualitas dan peningkatan pelayanan merupakan bagian yang penting dalam strategi pemasaran. Meskipun demikian, hanya memfokuskan diri pada pelayanan rumah sakit akan membuat rumah sakit kurang memperhatikan faktor lainnya dalam pemasaran. Pengertian pelayanan pasien BPJS adalah pelayanan dan jasa yang dibeli oleh pasien BPJS dengan tujuan untuk konsumsi pribadi. Sedangkan kualitas adalah suatu kondisi dari sebuah barang berdasarkan pada penilaian atas kesesuaiannya dengan standar ukur yang telah ditetapkan (Handoko, 2005). Loyalitas sebagai kemauan pelanggan untuk terus mendukung sebuah rumah sakit dalam jangka panjang membeli dan menggunakan pelayanan dan jasanya atas dasar rasa suka yang eklusif dan secara sukarela merekomendasikan pelayanan rumah sakit kepada orang lain.

Salah satu alasan kenapa terjadi perpindahan pelanggan dari satu rumah sakit jasa ke rumah sakit yang lain adalah karena pelanggan tidak puas dengan penyelesaian masalah atau cara menghadapi masalah dari rumah sakit jasa tersebut "Dealing with customer 
complaints over the way services are provided by a rumah sakit" (Tronvoll, 2007). Ketika pelanggan merasa tidak puas dengan apa yang diterima atau pada saat menemui masalah, pelanggan mungkin akan merespon dengan keluar beralih pada penyedia jasa lain, suara (mencoba untuk memecahkan masalah dengan menyampaikan keluhan atau komplain) atau bersikap setia, tetap bersama penyedia jasa tersebut dan berharap dikemudian hari ada perubahan (Hirschman, 2012) dan (Rokhyadi, Haryono, \& Untoro, 2015).

Hasil penelitian yang dilakukan oleh Endriyastono (2014), Suparno (2014), Rustika Atmawati danWahyudi (2009), Karsono (2005), Palilati (2007), Wenny dan Halim (2008), Supardi (2008), Jan (2006), Eva Monica (2014), menunjukkan bahwa kualitas pelayanan berpengaruh signifikan terhadap loyalitas. Hasil penelitian yang dilakukan oleh Endriyastono (2014), Henri (2005), Wenny dan Halim (2008), Semuel dan Wijaya (2009), Kristian Suhartadi (2014), menunjukkan bahwa kualitas pelayanan berpengaruh signifikan terhadap kepuasan. Hasil penelitian yang dilakukan oleh Sunarti (2007), Supardi (2008), menunjukkan bahwa kualitas pelayanan berpengaruh tidak signifikan terhadap kepuasan.

Kesenjangan antara teori hubungan antara kualitas pelayanan terhadap loyalitas dan kepuasan dengan temuan hasil penelitian (teori gap) dan kesenjangan antara temuan hasil penelitian (riset gap) telah menimbulkan rasa ingin tahu untuk mengkaji lebih mendalam hubungan ke dua variabel yaitu pengaruh antara kualitas pelayanan terhadap kepuasan dan loyalitas pasien BPJS merupakan arah pengaruh yang dikaji dalam penelitian ini.

Citra rumah sakit secara umum adalah suatu gambaran psikologis yang terbentuk dalam pikiran pasien BPJS yang dihasilkan dari banyaknya rangsangan yang berbeda-beda terhadap setiap inderanya. Penanganan komplain pasien BPJS rumah sakit saat ini menjadi salah satu kunci utama suatu rumah sakit dapat terus tumbuh dan berkembang, karena apabila pasien BPJS merasa tidak mendapatkan layanan yang baik saat menyampaikan keluhan maka pasien BPJS akan dengan mudahnya untuk berpindah ke rumah sakit lain yang dianggap bisa memberikan layanan terhadap komplain dengan baik.

Setiap rumah sakit mempunyai citra yang disadari atau tidak telah melekat pada rumah sakit tersebut, tidak sedikit barang atau jasa yang dihasilkan rumah sakit begitu kuat citranya dibenak pasien BPJSnya. Menurut Tjiptono (2009), citra rumah sakit merupakan bagian dari konsep rumah sakit (Corporate Image) dimana Corporate Image merupakan bagian dari konsep kualitas total jasa. Sedangkan menurut Margaretha (2014) menganggap citra rumah sakit sebagai salah satu faktor terpenting dari karakteristik rumah sakit yang dapat membentuk kepercayaan pasien BPJS terhadap pelayanan yang diberikan.

Hasil penelitian yang dilakukan Kristian Suhartadi (2014) menunjukkan bahwa ekuitas merek atau citra berpengaruh signifikan terhadap kepuasan. Hasil penelitian yang dilakukan oleh Setyo Budiarto (2011) menunjukkan bahwa citra berpengaruh tidak signifikan terhadap kepuasan dan loyalitas. Hasil penelitian yang relevan dilakukan oleh Kristian Suhartadi (2014) menunjukkan bahwa citra berpengaruh tidak signifikan terhadap loyalitas. Adanya kesenjangan antara teori dan hasil penelitian yang relevan, serta kesenjangan antara hasil temuan penelitian penelitian, maka dalam penelitian ini akan diuji kembali pengaruh antara citra terhadap kepuasan dan loyalitas.

Penanganan komplain pasien BPJS rumah sakit saat ini menjadi salah satu kunci utama suatu rumah sakit dapat terus tumbuh dan berkembang, karena apabila pasien BPJS merasa tidak mendapatkan layanan yang baik saat menyampaikan keluhan maka pasien BPJS akan dengan mudahnya untuk berpindah ke rumah sakit lain yang dianggap bisa memberikan layanan terhadap komplain dengan baik (Nyer, 2008). Penanganan komplain pasien BPJS rumah sakit saat ini menjadi salah satu kunci utama suatu rumah sakit dapat terus tumbuh dan berkembang, karena apabila pasien BPJS merasa tidak mendapatkan layanan yang baik saat menyampaikan keluhan maka pasien BPJS akan dengan mudahnya untuk berpindah ke rumah sakit lain yang dianggap bisa memberikan layanan terhadap komplain dengan baik (Nyer, 2008). Adanya kesenjangan antara teori dan hasil penelitian yang relevan, serta 
kesenjangan antara hasil temuan penelitian penelitian, maka dalam penelitian ini akan diuji kembali pengaruh antara penanganan komplain terhadap kepuasan dan loyalitas.

\section{METODE PENELITIAN}

Populasi dalam penelitian ini adalah pasien BPJS di RSUI Amal Sehat, Sragen sejumlah 800 pasien BPJS yang datang periksa pada bulan Nopember - Desember 2016. Menurut Arikunto (2007:120), jika jumlah subyeknya (populasinya) kurang dari 100 sampel maka sebaiknya semua populasi diambil sebagai sampel penelitian, jika sampelnya lebih dari 100, maka dapat ditentukan berdasarkan prosentase, misalnya $10 \%-20 \%$ atau $20 \%-30 \%$, menurut kemampuan peneliti. Sampel dalam penelitian ini adalah sebesar $10 \%$ dari populasi yaitu sebesar 80 pasien BPJS yang datang periksa pada bulan Nopember dan Desember 2016 di RSUI Amal Sehat, Sragen. Teknik analisis statistik yang digunakan dalam penelitian ini adalah jalur (path analisis).

\section{HASIL DAN PEMBAHASAN}

Pengaruh Langsung dan Pengaruh Tidak Langsung dan Total Pengaruh.

Analisis jalur memperhitungkan pengaruh langsung dan tidak langsung maupun pengaruh total. Adapun hasil analisis jalur adalah sebagai berikut:

\section{Tabel 1. Pengaruh Langsung, Pengaruh Tidak Langsung Dan Total Pengaruh}

\begin{tabular}{|c|c|c|c|}
\hline \multirow[b]{2}{*}{ Dari Variabel } & \multicolumn{2}{|c|}{ Koefisien Jalur } & \multirow[b]{2}{*}{$\begin{array}{c}\text { Total } \\
\text { Pengaruh }\end{array}$} \\
\hline & $\begin{array}{l}\text { Pengaruh } \\
\text { Langsung }\end{array}$ & $\begin{array}{l}\text { Pengaruh Tidak } \\
\text { Langsung }\end{array}$ & \\
\hline $\begin{array}{l}X_{1} \operatorname{ke} Y \\
X_{2} \operatorname{ke} Y \\
X_{3} \operatorname{ke~} Y\end{array}$ & $\begin{array}{l}=P_{4}=0,309 \\
=P_{5}=0,309 \\
=P_{6}=0,107\end{array}$ & & \\
\hline $\begin{array}{l}\mathrm{X}_{1} \text { melalui } \mathrm{X}_{4} \mathrm{Ke} \mathrm{Y} \\
\mathrm{X}_{2} \text { melalui } \mathrm{X}_{4} \mathrm{Ke} \mathrm{Y}\end{array}$ & & $\begin{array}{l}=P_{1} \times P_{9} \\
=0,357 \times 0,060 \\
=0,021 \\
=P_{2} \times P_{9} \\
=0,414 \times 0,060 \\
=0,024 \\
=P_{3} \times P_{9} \\
=0,137 \times 0,060 \\
=0,008\end{array}$ & $\begin{array}{l}=P_{4}+\left(P_{1} \times P_{9}\right) \\
=0,309+0,021 \\
=0,330 \\
=P_{5}+\left(P_{2} \times P_{9}\right) \\
=0,309+0,024 \\
=0,333 \\
=P_{6}+\left(P_{2} \times P_{9}\right) \\
=0,107+0,008 \\
=0,115\end{array}$ \\
\hline
\end{tabular}

Kesimpulan pengaruh langsung dan tidak langsung adalah pengaruh langsung kualitas pelayanan terhadap loyalitas pasien bpjs dan citra terhadap loyalitas pasien BPJS lebih efektif dibandingkan pengaruh tidak langsung, sehingga untuk meningkatkan loyalitas pasien BPJS lebih efektif melalui jalur langsung.

\section{PEMBAHASAN}

\section{Implikasi Manajerial}

1. Pengaruh Kualitas Pelayanan Terhadap Loyalitas Pasien BPJS

Pengaruh langsung kualitas pelayanan terhadap loyalitas pasien BPJS lebih besar dibandingkan pengaruh tidak langsung, sehingga untuk meningkatkan loyalitas pasien BPJS lebih efektif melalui jalur langsung. Hal ini mengidentifikasikan bahwa Pasien BPJS pada RSUI Amal Sehat Sragen membutuhkan kualitas pelayanan yang baik dan harus memperhatikan faktor-faktor yang dapat meningkatkan kualitas pelayanan sehingga pasien BPJS akan tetap loyal terhadap RSUI Amal Sehat Sragen.

2. Pengaruh Citra rumah sakit Terhadap Loyalitas Pasien BPJS 
Pengaruh langsung citra rumah sakit terhadap loyalitas pasien BPJS lebih besar dibandingkan pengaruh tidak langsung, sehingga untuk meningkatkan loyalitas pasien BPJS lebih efektif melalui jalur langsung. Hal ini mengidentifikasikan bahwa Pasien BPJS pada RSUI Amal Sehat Sragen membutuhkan citra rumah sakit yang baik yang dapat dipercaya, sehingga membuat Pasien BPJS akan tetap loyal terhadap RSUI Amal Sehat Sragen.

3. Pengaruh Penanganan Komplain Terhadap Loyalitas Pasien BPJS

Pengaruh langsung penanganan komplain terhadap loyalitas pasien BPJS lebih besar dibandingkan pengaruh tidak langsung, sehingga untuk meningkatkan loyalitas pasien BPJS lebih efektif melalui jalur langsung. Hal ini mengidentifikasikan bahwa Pasien BPJS pada RSUI Amal Sehat Sragen membutuhkan penanganan komplain yang lebih baik dan lebih baik jika ingin meningkatkan loyalitas pasien BPJS. Hal ini berarti penanganan komplain perlu ditingkatkan agar loyalitas pasien BPJS akan meningkat.

\section{KESIMPULAN}

1. Hasil Uji t dapat disimpulkan bahwa:

a. Kualitas pelayanan berpengaruh positif dan signifikan terhadap Kepuasan Pasien BPJS.

b. Citra berpengaruh positif dan signifikan terhadap Kepuasan pasien BPJS.

c. Penangganan Komplain berpengaruh positif dan tidak signifikan terhadap Kepuasan Pasien BPJS.

d. Kualitas Pelayanan, Citra rumah sakit berpengaruh positif dan signifikan terhadap Loyalitas Pasien BPJS.

e. Kepuasan pasien BPJS dan penanggan komplain berpengaruh positif dan tidak signifikan terhadap Loyalitas Pasien BPJS.

2. Hasil uji $\mathrm{F}$ dapat disimpulkan secara bersama-sama variabel bebas berpengaruh signifikan terhadap Loyalitas pasien BPJS di RSUI Amal Sehat Sragen.

3. Nilai $\mathrm{R}^{2}$ total sebesar 0,763 , dapat diartikan Loyalitas Pasien BPJS RSUI Amal Sehat Sragen dijelaskan oleh variabel kualitas pelayanan, citra rumah sakit, penanganan komplain dan kepuasan Pasien BPJS sebesar 76,3\% dan sisanya 23,7\% dijelaskan variabel lain diluar model penelitian.

4. Hasil analisis jalur menunjukkan bahwa pengaruh langsung kualitas pelayanan terhadap loyalitas pasien BPJS dan Citra terhadap loyalitas pasien BPJS lebih efektif dibandingkan pengaruh tidak langsung, sehingga untuk meningkatkan loyalitas pasien BPJS lebih efektif melalui jalur langsung.

5. Kualitas pelayanan merupakan variabel paling dominan dalam meningkatkan Loyalitas pasien BPJS di RSUI Amal Sehat Sragen.

\section{SARAN}

Berdasarkan hasil penelitian disarankan hal-hal sebagai berikut:

1. Citra rumah sakit merupakan variabel yang paling dominan mempengaruhi Loyalitas Pasien BPJS RSUI Amal Sehat Sragen. Untuk itu akan lebih baik apabila RSUI Amal Sehat Sragen dalam peningkatan Loyalitas Pasien BPJS lebih meningkatkan kualitas pelayanan yang lebih baik lagi upaya yang dapat dilakukan antara lain adalah sebagai berikut:

a. Rumah sakit memiliki citra yang bagus bila dibandingkan dengan rumah sakit lain, misalnya memberikan jaminan pelayanan yang lebih baik sehingga memberikan citra yang baik di mata masyarakat.

b. Rumah sakit memiliki citra yang bagus dengan manajemen modern, misalnya peralatan yang digunakan untuk pasien BPJS sama dengan pelayanan yang diberikan kepada pasien umum. 
c. Pasien BPJS percaya rumah sakit memiliki citra yang bagus, misalnya mampu memberikan kepercayaan kepada pasien, sehingga pasien tidak merasa ragu untuk datang berobat di RSUI Amal Sehat Sragen.

2. Sebaiknya kepuasan pasien BPJS lebih diperhatikan kembali, agar hasilnya meningkat supaya menjadi variabel intervening yang lebih efektif.

\section{DAFTAR PUSTAKA}

Anderson, E. and B. Weitz, 2003, "The Use of Pledges to Build and Sustain Commitment in Distribution Channel", Journal of Marketing research 29 (1), p.18-34.

Arikunto, Suharsini, 2001. Prosedur Penelitian Suatu Pendekatan Praktek Edisi ketiga.

Budiarti, Anindhyta, 2009.Pengaruh Kualitas Layanan Dan Penanganan Keluhan Terhadap Kepuasan Dan Loyalitas Nasabah Bank Umum Syariah Di Surabaya. Ekuitas Vol. 15 No. 2 Juni 2011: $210-231$

Bolton, Ruth N and james H. Drew, 2001, " A Multi Stage Model of Customers Assessment of Service Quality and Value", Journal of Consumer Research, Januari, 1-9.

Bontis, Nick and Lorne D.Booker (2007), "The mediating effect of organizational reputation on customer loyalty and service recommendation in rumah sakiting industry", Journal Management Decion, Vol.45, No.9 p.1426-1445.

Brown, Stephen W., 2001, "A Multi Stage Model of Customers Assesment of Service Quality and Value", Journal of Marketing, April, pp. 92-98

Cronin J.Joseph Jr and Steven A. Taylor (2002), " Measuring Service Quality : A reexamination and extension", Journal of Marketing Vol. 56 (July) p.55-68

Djarwanto dan Subagyo, Pangestu, 2001: Statistik Induktif, Edisi: 4, Yogyakarta: BPFE.

Fornell, Claes; Johnson, Michael D ; Anderson, Eugene W ; Cha, Jaesun; Bryant, Barbara Everitt (2006), "The American Customer Satisfaction Index : Nature, Purpose, and Findings". Journal of Marketing, 60 (10). (7-18).

Ghozali, Imam,2004. Aplikasi Analisis Multivariate Dengan Program SPSS

2006. Analisis Regresi. Jakarta: Salemba Empat.

Gujarati, Damodar. 2005. Ekonometrika Dasar. Erlangga. Jakarta.

Herbig, Paul, John Milewicz and Jim Golden,(2004). "A Model of Reputation Building and Destruction "Journal of Business Research. Vol.31, June 1994, No. 1 ; p.23-31.

Istijanto, 2006, Riset Sumber Daya Manusia, Jakarta:PT. Gramedia Pustaka Utama

Juran, J.M., 2001, Quality Control Handbook, New York: Mc. Graw-Hill.

Kotler, Philip.(2003), Marketting Management, $11^{\text {th }}$ ed. Upper Saddle River, New Jersey : Prentice Hall, Inc.

Liu, Tsung-Chi and Li Wei Wu (2007), "Customer retention and cross-buying in the rumah sakiting industry : An Integration of service attributes, satisfaction and trust" Journal of Financial Service Marketing, Vol.12 No.2 p.132-145. 
Marius, 2009, Consumer Behavion and Price, $5^{\text {th }}$ edition, McGraw Hill, New York, NY

Mandela, (2007), "Study Mengenai Loyalitas Pasien Pada Rumah Makan Start Stick (Studi khusus di Jawa Tengah)", Jurnal Sains Pemasaran Indonesia, Vol III, No.3, Desember 2007. (289-308)

Oliver, Richard L. (2007), "Satisfaction : A Behavioral Perspective on the Customer", McGraw-Hill, New York, NY

Parasuraman, A.,A.Zeithmal, V.,\& L.Berry, L.2005" A conceptual Model of Service Quality and Its Implications for Future Research", Journal of Marketing, Vol.49 (fall).

Peraturan Pemerintah Republik Indonesia No.25 tahun 1980 tentang perubahan atas Peraturan Pemerintah No. 26 tahun 1965 tentang Rumah sakit.

Prichard, mark P, 2000, "Analyzing the Commitment-Loyalty Link in Service Contexts", Journal of the Academy of Marketing Science 27 (3), p.333-348

Riduwan, 2005, Skala pengukuran Variabel-Variabel Penelitian, Cetakan Ketiga, Alfabeta, Bandung.

Rokhyadi, A., Haryono, T., \& Untoro, W. (2015). Impact of company's performance and green strategy on organizational culture: Phenomenon of Indonesia. International Journal of Research In Commerce \& Management, 6(11), 1-7.

Selnes, Fred (2003), "An Examination of the effect of Product Performance on Brand Reputation, Satisfaction and Loyalty", European Journal of Marketing, 27 (9). (1935).

Setyo, Budiarto, 2001, "Pengaruh Kualitas Pelayanan terhadap Loyalitas Pasien dan Citra rumah sakit sebagai Variabel Intervening pada Apotek K-24 Jogjakarta" Pustaka Pelajar, Yogyakarta.

Solomon, Michael (2006), Consumer Behavion, $3^{\text {th }}$ edition, McGraw Hill.

Sugiyono, 2001. Metodologi Penelitian Bisnis, Cetakan Keenam, CV. Alpabeta, Bandung.

Tjiptono, Fandi, 2002, Prinsip-prinsip Total Quality Service (TQS) , Andi Offset, Yogyakarta.

Victor Salay, 2010. Pengaruh Kualitas Layanan Dan Penanganan Komplain Terhadap Kepuasan Nasabah Pada Loyalitas Nasabah Pada Bank BRI Cabang Kertajaya Di Surabaya. Jurnal Bisnis and Managemen. UNS Surakarta.

Zeithaml, V.(2008), Consumer Perceptions of Price, "Quality, and Value : Means End Model and Synthesis of Evidence", Journal of Marketing, Vol 52, July, p.2-22

Zeithaml, Valerie; Berry, Leonard L,; and Parasuraman, A. (2008), "Sevqual: Multiple Item Scale for Measuring Consumer Perceptions of Service Quality", Journal of Retailing, Vol 64 No. 1 Spring. 